\title{
Composição corporal e exigências líquidas de proteína e energia de bovinos de quatro grupos genéticos terminados em confinamento ${ }^{1}$
}

\author{
Rodrigo Silva Goulart ${ }^{2}$, Maurício Mello de Alencar ${ }^{3}$, Edison Beno Pott ${ }^{3}$, Geraldo Maria da Cruz ${ }^{3}$, \\ Rymer Ramiz Tullio ${ }^{3}$, Guilherme Fernando Alleoni ${ }^{4}$, Dante Pazzanese Duarte Lanna ${ }^{5,6}$
}

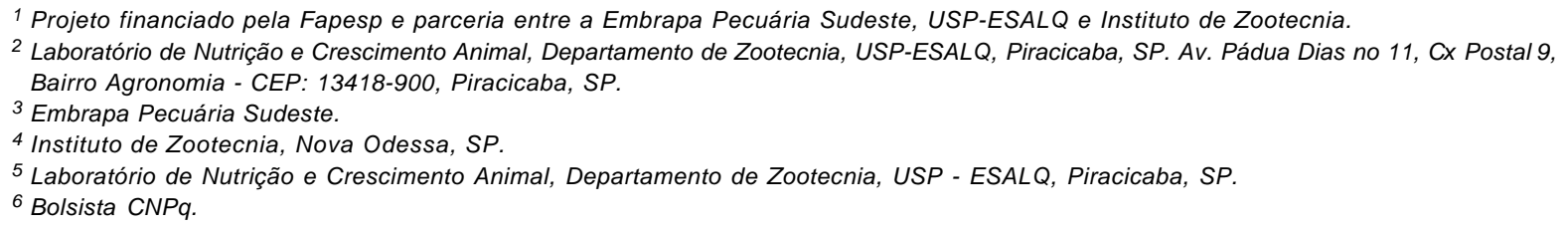

RESUMO - Objetivou-se neste estudo avaliar a composição corporal e as exigências para crescimento de bovinos de quatro grupos genéticos em confinamento. Utilizou-se a metodologia de abate comparativo, com delineamento inteiramente ao acaso, com quatro tratamentos: Nelore (NE), 1/2 Aberdeen Angus $+1 / 2$ Nelore (AN), 1/2 Canchim $+1 / 2$ Nelore $(\mathrm{CN}$ ) e $1 / 2$ Simental $+1 / 2$ Nelore (SN). Quarenta e sete animais castrados, com média de 22 meses de idade e peso em jejum de $310 \mathrm{~kg}$, foram confinados por 101 dias. A dieta experimental continha 13,34\% de proteína bruta (PB) e 71,81\% de nutrientes digestíveis totais (NDT). A composição do corte da 9â-10 -11 a costelas foi utilizada para estimar a composição do corpo vazio. Bovinos AN (428 kg) e SN (410 kg) não diferiram quanto ao peso final de corpo vazio, que foi semelhante também entre os animais CN, NE e SN (389, 390 e $410 \mathrm{~kg}$, respectivamente). Animais AN tiveram maior proporção de gordura no corte das costelas, porém menor proporção de músculo.A menor porcentagem de ossos no corte das costelas foi observada nos animais da raça Nelore. Os grupos AN e SN tiveram maior proporção de extrato etéreo (EE) e menor porcentagem de água no corpo vazio no momento do abate. Animais AN, NE e SN não diferiram quanto à taxa de deposição de energia (6,06, 5,20 e 5,80 Mcal/dia, respectivamente). $\mathrm{O}$ grupo $\mathrm{AN}$ não diferiu dos grupos $\mathrm{CN}$ e SN quanto à proporção de EE na composição do ganho de peso do corpo vazio. Bovinos SN apresentaram maior exigência de proteína $(0,164 \mathrm{~kg} / \mathrm{kg}$ de ganho de peso vazio - GPV) e os animais AN e CN, o menor valor $(0,140$ e $0,142 \mathrm{~kg} / \mathrm{kg}$ de GPV, respectivamente). Animais AN tiveram a maior exigência líquida de energia para ganho $(4,685 \mathrm{Mcal} / \mathrm{kg}$ de GPVz).

Palavras-chave: bovinos de corte, composição corporal, cruzamento, exigências líquidas, Nelore, taxas de deposição

\section{Body composition and protein and energy net requeriments of steers of four genetic groups finished in feedlot}

\begin{abstract}
The body composition and protein and energy requirements for growth of steers of four genetic groups finished in feedlot were evaluated in this experiment. comparative slaughter method was used in a completely randomly experimental design, with four treatments: Nellore (NE), 1/2 Aberdeen Angus $+1 / 2$ Nellore (AN), 1/2 Canchim $+1 / 2$ Nellore $(\mathrm{CN})$ e $1 / 2$ Simmental $+1 / 2$ Nellore (SN). Forty-seven steers averaging $310 \mathrm{~kg}$ initial shrunk body weight (SBW) and 22 months were fed during 101 days in a feedlot. Diet on feedlot had the following composition: crude protein, 13.34\%; rumen degradable protein, $9.35 \%$; and total digestible nutrients, $71.81 \%$ (estimated value). Composition of the $9^{\text {th }}-10^{\text {th }}-11^{\text {th }}$ ribs was used to calculate empty body composition. No significant differences were found between AN ( $428 \mathrm{~kg})$ and SN (410 kg) in final empty body weight (EBW), and similarly among CN, NE and SN (389, 390 and $410 \mathrm{~kg}$, respectively), but EBW of AN steers was greater than that of $\mathrm{CN}$ and NE cattle. AN steers had higher amount of fat percentage on rib cut. However, less proportion of muscle was observed in the AN group and less bone percentage at the rib cut of the Nelore breed. AN and SN groups had the largest concentration of ether extract and the smallest amount of water percentage on the empty body at slaughter. Steers of AN, $\mathrm{NE}$ and SN groups were similar in rate of energy deposition (6.06, 5.20 and $5.80 \mathrm{Mcal} /$ day, respectively). There was no difference among AN and CN cattle on ether extract in empty body weight gain. Simmental $\times$ Nelore demonstrated the greatest requirements of protein $(0.164 \mathrm{~kg} / \mathrm{kg}$ of EWG), and $\mathrm{AN}$ and $\mathrm{CN}$ cattle $(0.140$ and $0.142 \mathrm{~kg} / \mathrm{kg}$ of EWG, respectively), the smallest. Angus $\times$ Nelore animals required the greatest net energy for gain (4.685 Mcal/kg of EWG).
\end{abstract}

Key Words: beef cattle, body composition, crossbreeding, deposition rate, Nelore, net requirements

Este artigo foi recebido em 21/12/2006 e aprovado em 7/11/2007.

Correspondências devem ser enviadas para rodrigosg21@yahoo.com.br. 


\section{Introdução}

A composição química do corpo vazio de um animal é o resultado das influências hereditárias (genéticas) e do ambiente (Reid et al., 1955). Avaliações que envolvem raças ou grupos genéticos quanto à composição corporal e às exigências nutricionais são condições essenciais para a melhoria do desempenho produtivo e econômico do rebanho brasileiro, e devem ser conduzidas dentro das condições do ambiente (manejo) em que os animais serão explorados.

Sabe-se que grupos genéticos apresentam diferentes taxas e eficiências de deposição dos constituintes químicos corporais (NRC, 1996), quando comparados à mesma idade, ao mesmo peso ou ao mesmo grau de acabamento. Também há interação entre estas variáveis e o tipo de manejo e o sistema alimentar. Dessa forma, uma boa estimativa da composição corporal torna-se imprescindível (Ferrell \& Jenkins, 1984).

As diferenças nas exigências de energia e de proteína para ganho entre diferentes raças bovinas estão relacionadas a variações na composição do ganho de peso, porque os requisitos líquidos de energia para crescimento são função da proporção de gordura e de proteína no ganho do corpo vazio. As exigências líquidas de proteína, no entanto, são função do conteúdo da matéria seca (MS) livre de gordura do peso ganho (Garret et al., 1959). À medida que a idade avança, eleva-se a exigência de energia para ganho de peso e diminui a de proteína. Reid et al. (1980), em estudo do efeito da composição do corpo vazio entre raças, concluíram que a deposição de proteína na carcaça é menos pronunciada, ao mesmo peso, em raças de maturidade fisiológica precoce, quando comparada às de maturidade tardia.

O conhecimento da composição corporal permite desenvolver modelos matemáticos para simular o crescimento de diferentes grupos genéticos. Isto possibilita es timar a eficiência biológica e econômica da atividade em diversas condições de nutrição, de ambiente e de manejo (Lanna et al. 1997). Nesse cenário, poucos trabalhos foram conduzidos para comparar a composição em zebuínos e seus mestiços no mesmo sistema de criação oriundos do mesmo rebanho de matrizes. Assim, objetivou-se avaliar o efeito do grupo genético nas exigências líquidas de ganho de diferentes grupos genéticos de mesmo rebanho criados e recriados no mesmo sistema de produção.

\section{Material e Métodos}

O experimento foi conduzido na Embrapa Pecuária Sudeste, em São Carlos, São Paulo, no período de julho a outubro de 2004. Todos os animais destinados ao experimento foram oriundos do mesmo lote de fêmeas da raça Nelore e foram tratados desde o nascimento até o final da recria (início do experimento) com mesmo manejo e o mesmo sistema alimentar.

Utilizou-se a metodologia de abate comparativo, com delineamento inteiramente ao acaso, com quatro tratamentos: Nelore (NE), 1/2 Aberdeen Angus + 1/2 Nelore (AN), 1/2 Canchim $+1 / 2$ Nelore $(\mathrm{CN})$ e $1 / 2$ Simental $+1 / 2$ Nelore $(\mathrm{SN})$. Para obter maior variabilidade genética, foram utilizados touros ou sêmen de várias origens (dois da raça Nelore e cinco da raça Canchim) e sêmen de oito touros da raça Aberdeen Angus e de 12 touros da raça Simental. Quarenta e sete animais castrados nascidos na primavera de 2002 com 22 meses \pm 23 dias de idade e peso corporal de $312 \pm$ $30 \mathrm{~kg}$ foram utilizados no experimento. Quatro bovinos de cada grupo genético (GG) foram selecionados para serem abatidos no início do confinamento (linha-base) e serviram como referência no estudo da composição corporal inicial dos animais. Os 31 animais restantes destinados ao período de alimentação foram distribuídos da seguinte forma: oito animais para os grupos $\mathrm{AN}, \mathrm{CN}$ e $\mathrm{NE}$ e sete animais para os grupos SN.

Durante o confinamento, não houve período de adaptação, pois o objetivo foi avaliar o desempenho dos animais de maneira semelhante ao de confinamentos comerciais; assim, os dados representam o período integral de confinamento. Todas as pesagens dos animais foram realizadas com jejum de 16 horas (retirada de água e alimento).

Os animais foram alimentados ad libitum em baias individuais, duas vezes ao dia, às 8 e às $16 \mathrm{~h}$. O consumo de MS foi monitorado diariamente, com controle diário do oferecido e das sobras. Avaliações semanais dos teores de MS dos ingredientes da ração foram realizadas para os ajustes da composição da ração (Tabela 1).

A dieta continha $60 \%$ de silagem de milho e $40 \%$ de concentrado na MS (Tabela 1) e foi balanceada de acordo com RLM 2.0 (Lanna et al., 1999) para conter 13,34\% de PB, 9,35\% de proteína degradável no rúmen e 71,81\% de nutrientes digestíveis totais (valor estimado). O balanceamento permitiu atender às exigências de proteína degradável, de proteína metabolizável, de macrominerais e de microminerais estabelecidas pelo NRC (1996) para o GG de maior exigência (Simental $\times$ Nelore).

Os alimentos e as sobras por baia foram analisados quanto aos teores de MS, proteína bruta (PB), fibra insolúvel em detergente neutro (FDN), nitrogênio insolúvel em FDN (N-FDN), fibra insolúvel em detergente ácido (FDA), nitrogênio insolúvel em FDA (N-FDA), lignina em ácido sulfúrico, cinzas e extrato etéreo (EE). Não foi utilizado 
Tabela 1 - Composição da dieta experimental (\% MS)

\begin{tabular}{lc}
\hline Ingrediente & $\%$ da MS \\
\hline Silagem de milho & 60 \\
Polpa cítrica & 20 \\
Farelo de algodão (38\%PB) & 10,3 \\
Milho moído & 7,8 \\
Uréia & 0,9 \\
Mistura mineral & 1 \\
Nutrientes digestíveis totais (\% na MS)* & 68,69 \\
Energia metabolizável (Mcal/kg de MS) & 2,59 \\
Proteína bruta (\% na MS) & 13,34 \\
Proteína degradável no rúmen (\% na MS) & ** \\
\hline
\end{tabular}

sulfito na solução de FDN e todas as análises foram realizadas de acordo com as normas da AOAC (1995).

Os valores de nutrientes digestíveis totais (NDT) foram estimados por meio da equação desenvolvida por Weiss et al. (1992), conforme citado pelo NRC (2001): NDT $=(0,98 \times$ CNF $)+$ PDisp. $+[(2,8 \times($ EE - 1) $]+0,82 \times($ FDNLP - L $) \times\{1-$ $\left.\left.\left[(\mathrm{L} / \mathrm{FDNLP})^{\wedge} 0.667\right)\right]\right\}-9$; em que $\mathrm{CNF}=$ carboidratos nãofibroso, Pdisp. = proteína disponível, FDNLP = fibra insolúvel em detergente neutro livre de proteína e $\mathrm{L}=$ lignina.

A metodologia de abate foi a mesma, tanto para os animais do início (linha-base) como os do final do confinamento: os animais foram abatidos à mesma idade, após 101 dias de alimentação. O abate foi realizado por concussão cerebral, com pistola de ar comprimido, seguida de secção da jugular e esfola pelo método tradicional de tracionamento mecânico por corrente.

Após o abate, obteve-se na carcaça quente o peso sem a presença da gordura renal e pélvica. Depois de 24 horas de resfriamento, a carcaça foi novamente pesada e a espessura de gordura subcutânea foi medida no corte transversal entre a $12 \underline{\text { a e a } 13}$ a costela.

Do lado esquerdo da carcaça resfriada, foi retirada a secção da 9â-10â-11a costelas, segundo metodologia de Hankins \& Howe (1946). Essas amostras foram encaminhadas para o Laboratório de Referência na Classificação e na Análise de Carcaça do Instituto de Zootecnia de Nova Odessa para a separação física do corte das costelas.

Após a retirada do corte das costelas, foi feita a separação e a pesagem de músculos, ossos, cartilagens e gordura para obtenção da composição física do corte da 9â-10a-1 $11^{\text {a }}$ costelas. As amostras foram moídas três vezes em peneiras com malha de $30 \mathrm{~mm}$ e três vezes em peneiras com malha de $12 \mathrm{~mm}$. Em seguida, uma subamostra previamente moída e homogeneizada foi liofilizada até peso constante para obtenção do teor de água. Após a liofilização, aproximadamente $400 \mathrm{~g}$ de amostra foram moídos com gelo seco e analisados quanto à composição em MS, EE, PB e matéria mineral, de acordo com as normas da AOAC (1995). Uma segunda determinação de MS em estufa a $105^{\circ} \mathrm{C}$ foi realizada no material liofilizado, que apresentava aproximadamente $5 \%$ de umidade.

Utilizou-se o método de Soxhlet para determinação do EE com 24 horas de extração em éter de petróleo. O teor de PB foi determinado pelo aparelho LECO FP-528 e a quantidade de nitrogênio foi multiplicada pelo fator 5,88 (Baldwin, 1995). A matéria mineral foi determinada pela queima da amostra em mufla a $550^{\circ} \mathrm{C}$ durante 8 horas.

Em virtude da alta correlação entre a composição química do corte da 9a-10a-11 1 a costelas e a do corpo vazio (Alleoni et al., 1997; Henrique et al., 2003; Lanna et al., 1995; Nour \& Thonney, 1994), foram utilizadas equações para estimativa da composição de água e EE do corpo vazio, de acordo com a porcentagem de água do corte das costelas.Foram utilizadas as equações de regressão linear desenvolvidas por Berndt (dados não publicados) em pesquisa com bovinos não-castrados de mesmos grupos genéticos utilizados neste trabalho. Os animais deste experimento, no entanto, eram castrados e as equações não foram validadas para esses animais. Por outro lado, em razão da ausência de equações na literatura científica para estimar a composição do corpo vazio de diferentes grupos genéticos criados em mesmo rebanho e sob manejo semelhante ao deste experimento, utilizaram-se as equações desenvolvidas por Berndt (dados não publicados). Essa escolha se deu em virtude da semelhança do sistema de cruzamentos adotado no experimento de Berndt e pelo fato de esses animais serem oriundos do mesmo lote de fêmeas da raça Nelore.

Equações:

Aberdeen Angus $\times$ Nelore

Extrato etéreo no corpo vazio $(\%)=-0,661 \times$ água no corte $(\mathrm{em} \%)+54,273, \mathrm{r}^{2}=0,8325$.

Água no corpo vazio $(\%)=0,5516 \times$ água no corte $(\mathrm{em} \%)+30,347, \mathrm{r}^{2}=0,8935$.

Canchim $\times$ Nelore

Extrato etéreo no corpo vazio $(\%)=-0,7155 \times$ água no corte $(\mathrm{em} \%)+57,386, \mathrm{r}^{2}=0,8505$.

Água no corpo vazio $(\%)=0,5757 \times$ água no corte $(\mathrm{em}$ $\%)+28,499, \mathrm{r}^{2}=0,8795$.

Nelore

Extrato etéreo no corpo vazio $(\%)=-0,7291 \times$ água no corte $(\mathrm{em} \%)+57,498, \mathrm{r}^{2}=0,9093$. 
Água no corpo vazio $(\%)=0,6108 \times$ água no corte $(\mathrm{em} \%)+27,173, \mathrm{r}^{2}=0,9246$.

Simental $\times$ Nelore

Extrato etéreo no corpo vazio $(\%)=-0,7672 \times$ água no corte $(\mathrm{em} \%)+61,125, \mathrm{r}^{2}=0,9128$.

Água no corpo vazio $(\%)=0,6822 \times$ água no corte $(\mathrm{em} \%)+21,003, \mathrm{r}^{2}=0,9179$.

Uma vez estimada a porcentagem de água e EE com essas equações, foram determinados os teores de proteína e de cinzas do corpo vazio utilizando-se a proporção fixa de 80,26:19,74 na MS desengordurada, como sugerido por Reid et al. (1955).

Lofgreen et al. (1962) afirmaram que o peso do corpo vazio de bovinos de corte poderia ser estimado por meio do peso da carcaça quente. Assim, foram utilizadas as equações de regressão linear desenvolvidas por Berndt (dados não publicados) para estimar o peso do corpo vazio a partir do peso da carcaça quente para cada grupo genético.

\section{Equações}

\section{Aberdeen Angus $\times$ Nelore}

Peso do corpo vazio $=1,4021 \times$ peso da carcaça quente $+45,069, \mathrm{r}^{2}=0,9948$.

Canchim $\times$ Nelore

Peso do corpo vazio $=1,3862 \times$ peso da carcaça quente $+43,889, \mathrm{r}^{2}=0,9877$.

Nelore

Peso do corpo vazio $=1,4305 \times$ peso da carcaça quente + $33,861, \mathrm{r}^{2}=0,9921$.

Simental $\times$ Nelore

Peso do corpo vazio $=1,465 \times$ peso da carcaça quente $+34,622, \mathrm{r}^{2}=0,9965$.

Os pesos de proteína e de gordura foram multiplicados por 5,686 e 9,367 Mcal/kg, respectivamente, para estimativa da retenção de energia (Mcal) no corpo vazio (Garrett et al., 1959). As quantidades de energia e de proteína retidas no ganho de peso do corpo vazio foram calculadas com base na composição corporal dos animais no início e a final do confinamento. Os dados foram submetidos à análise de variância pelo procedimento GLM,considerando os efeitos de GG, e as médias foram comparadas pelo LSMeans a 5\% de significância (SAS, 2001).

\section{Resultados e Discussão}

As comparações entre grupos genéticos foram realizadas à mesma idade e, conseqüientemente, a média de idade dos animais foi semelhante $(\mathrm{P}>0,05)$ (Tabela 2). No início do confinamento, os animais AN foram $37 \mathrm{~kg}$ mais pesados $(\mathrm{P}<0,05)$ que a média dos grupos NE e CN. Entretanto, não houve diferença $(\mathrm{P}>0,05)$ entre os grupos $\mathrm{AN}$ e $\mathrm{SN}$, embora os bovinos AN tenham sido $18 \mathrm{~kg}$ mais pesados que os de raça paterna continental (SN) (Tabela 2).

Os animais AN apresentaram maior consumo, em valores absolutos e em porcentagem do peso em jejum ( $\mathrm{P}<0,05)$, em comparação aos demais grupos genéticos (Tabela 2). A maior ingestão de MS pelos animais AN em relação ao peso em jejum sugere proporção maior de alimento usada para ganho.

Animais AN apresentaram o maior $(\mathrm{P}<0,05)$ peso final em jejum, o maior ganho de peso em jejum, o maior peso final de corpo vazio e o maior peso final da carcaça quente. Contudo, ao avaliar o ganho de peso do corpo vazio e o ganho de peso de carcaça quente, não foram observadas diferenças $(\mathrm{P}>0,05)$ entre os grupos AN e NE (Tabela 2). Os valores estimados do peso do corpo vazio apresentaram diferença igual à observada para peso em jejum e para peso da carcaça.

Apesar de os animais da raça Nelore terem ganhado menos peso em comparação àqueles dos grupos $\mathrm{AN}$ e SN (Tabela 2), a maior porcentagem deste ganho foi de carcaça $(\mathrm{P}<0,05)$. É possível que os animais NE tenham apresentado menor tamanho e menor conteúdo do trato gastrintestinal, no entanto, essas variáveis não foram avaliadas neste trabalho. Esses resultados estão de acordo com os dados do rendimento de carcaça ao abate, que foi maior $(\mathrm{P}<0,05)$ na raça NE (55\%) em comparação aos grupos AN e SN (53\%, em ambos os GG) (Tabela 2). Resultados similares foram encontrados por Putrino et al. (2006), que observaram maior proporção de carcaça no ganho de peso em jejum em animais Nelore $(53,67 \%)$ comparados a animais Brangus $(48,86 \%)$. Semelhantemente aos dados deste trabalho, Putrino et al. (2006) relataram que os animais Nelore tiveram também menor peso e menor ganho de peso quando comparados aos animais da raça Brangus.

Animais AN tiveram maior proporção de gordura separável no corte das costelas $(\mathrm{P}<0,05)$ se comparados aos demais grupos genéticos (Tabela 3), noentanto, apresentaram menor proporção de músculo $(\mathrm{P}<0,05)$. Em revisão, Reid (1972), citado por Fortin et al. (1980), estudou composição corporal de várias espécies e demonstrou que o componente mais variável é a gordura e que a variação de outros componentes foi reflexo das mudanças na proporção de gordura. 
O peso tem grande influência sobre a composição corporal, pois a proporção de gordura aumenta com o aumento do peso do animal. Assim, a maior proporção de gordura separável em animais AN pode ser explicada pelo maior peso de abate destes animais. Entretanto, mesmo não havendo diferença $(\mathrm{P}>0,05)$ no peso final entre os grupos
AN e SN e à mesma idade, animais dos cruzamentos com Angus apresentaram maior precocidade na deposição de gordura na carcaça em comparação àqueles da raça paterna continental. Essa afirmativa está de acordo com o valor de espessura de gordura subcutânea encontrado nesses dois grupos genéticos, que foi o dobro do obtido nos animais

Tabela 2 - Desempenho de bovinos de quatro grupos genéticos terminados em confinamento

\begin{tabular}{|c|c|c|c|c|c|c|}
\hline \multirow[t]{2}{*}{ Variável } & \multicolumn{4}{|c|}{ Grupo genético ${ }^{1}$} & \multirow[t]{2}{*}{ Coeficiente de variação } & \multirow[t]{2}{*}{ Erro-padrão } \\
\hline & AN & $\mathrm{CN}$ & $\mathrm{NE}$ & $\mathrm{SN}$ & & \\
\hline Idade de abate (dias) & $759 a$ & $743 a$ & $765 \mathrm{a}$ & $749 a$ & 3,11 & 8,3 \\
\hline Consumo de MS (kg MS/dia) & $12,74 \mathrm{a}$ & $10,74 b$ & $10,22 b$ & $11,27 b$ & 8,65 & 0,43 \\
\hline Consumo (\% do peso em jejum) & $2,59 \mathrm{a}$ & $2,37 \mathrm{~b}$ & $2,38 b$ & $2,32 b$ & 3,75 & 0,06 \\
\hline Peso em jejum inicial (kg) & $336 a$ & $302 b$ & $296 b$ & $318 \mathrm{ab}$ & 8,18 & 9,1 \\
\hline Peso em jejum ao abate (kg) & $508 \mathrm{a}$ & $453 b$ & $450 \mathrm{~b}$ & $476 a b$ & 7,32 & 12,2 \\
\hline Ganho de peso em jejum (kg/dia) & $1,70 \mathrm{a}$ & $1,50 \mathrm{~b}$ & $1,53 b$ & $1,56 \mathrm{ab}$ & 9,17 & 0,05 \\
\hline Peso de corpo vazio inicial $(\mathrm{kg})$ & $298 \mathrm{a}$ & $275 b$ & $262 b$ & $282 \mathrm{ab}$ & 8,66 & 7,6 \\
\hline Peso de corpo vazio ao abate $(\mathrm{kg})$ & $428 \mathrm{a}$ & $389 b$ & $390 \mathrm{~b}$ & $410 \mathrm{ab}$ & 7,9 & 10,4 \\
\hline Ganho de peso de corpo vazio (kg/dia) & $1,30 \mathrm{a}$ & $1,13 b$ & $1,28 \mathrm{a}$ & $1,28 \mathrm{ab}$ & 10,55 & 0,04 \\
\hline Peso de carcaça quente inicial (kg) & $180 \mathrm{a}$ & $167 \mathrm{ab}$ & $159 b$ & $168 \mathrm{ab}$ & 8,16 & 4,1 \\
\hline Peso de carcaça quente final (kg) & $273 a$ & $249 b$ & $249 b$ & $256 \mathrm{ab}$ & 7,76 & 7,6 \\
\hline Ganho de peso da carcaça quente (kg/dia) & $0,92 \mathrm{a}$ & $0,81 b$ & $0,90 \mathrm{ab}$ & $0,86 \mathrm{ab}$ & 10,58 & 0,03 \\
\hline Rendimento de carcaça quente $(\%)$ & $53 \mathrm{~b}$ & $54 \mathrm{ab}$ & $55 \mathrm{a}$ & $53 \mathrm{~b}$ & 1,99 & 0,4 \\
\hline
\end{tabular}

$1 \mathrm{NE}=$ Nelore $(\mathrm{n}=8), \mathrm{AN}=$ Aberdeen Angus $\times$ Nelore $(\mathrm{n}=8), \mathrm{CN}=$ Canchim $\times$ Nelore $(n=8), \mathrm{SN}=\mathrm{Simental} \times \mathrm{Nelore}(\mathrm{n}=7)$.

ab Letras distintas na mesma linha indicam diferença estatística pelo LSMeans a $5 \%$.

Tabela 3 - Composição física do corte da $9 \underline{a}-10 \underline{a}-11$ a costelas de quatro grupos genéticos em terminação

\begin{tabular}{|c|c|c|c|c|c|}
\hline \multirow[t]{2}{*}{ Variável } & \multicolumn{4}{|c|}{ Grupo genético $^{1}$} & \multirow[t]{2}{*}{ Erro-padrão } \\
\hline & AN & $\mathrm{CN}$ & NE & SN & \\
\hline Músculo no corte (\%) & $44,84 b$ & $48,35 \mathrm{a}$ & $48,90 \mathrm{a}$ & $48,00 \mathrm{a}$ & 1,13 \\
\hline Gordura no corte $(\%)$ & $38,49 a$ & $34,56 \mathrm{~b}$ & $34,41 \mathrm{~b}$ & $33,65 b$ & 1,29 \\
\hline Osso no corte $(\%)$ & $17,66 \mathrm{a}$ & $17,08 \mathrm{ab}$ & $16,68 b$ & $18,37 \mathrm{a}$ & 0,53 \\
\hline
\end{tabular}

$1 \mathrm{NE}=$ Nelore $(\mathrm{n}=8), \mathrm{AN}=$ Aberdeen Angus $\times$ Nelore $(\mathrm{n}=8), \mathrm{CN}=$ Canchim $\times$ Nelore $(n=8), \mathrm{SN}=\operatorname{Simental} \times$ Nelore $(n=7)$.

ab Letras distintas na mesma linha indicam diferença estatística pelo LSMeans a $5 \%$.

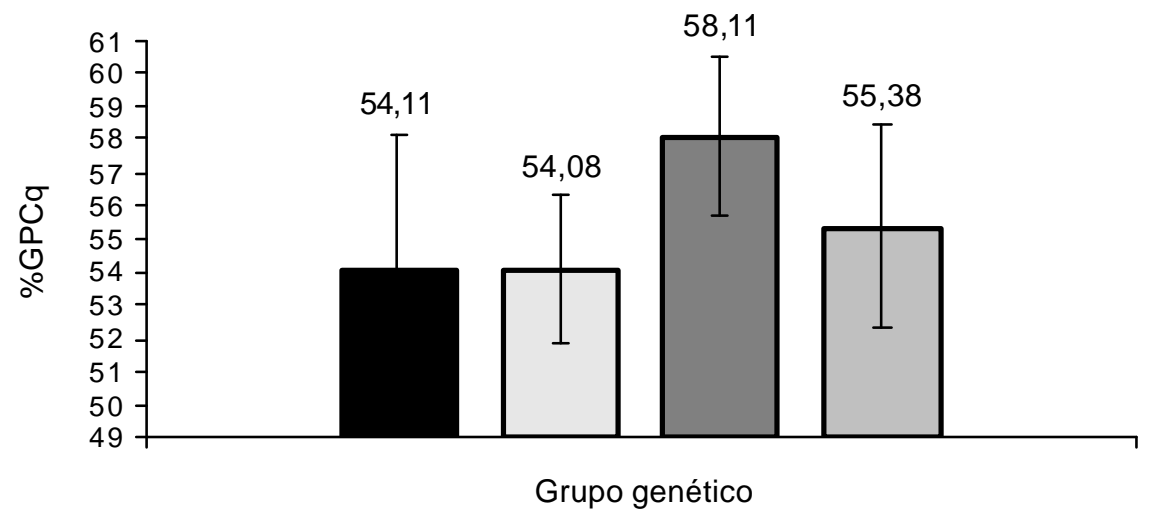

\section{AN $\square$ CN $\square$ NE $\square$ SN}

Figura 1 - Ganho de peso de carcaça quente (GPCq), em porcentagem do ganho de peso em jejum (GPj), em bovinos de quatro grupos genéticos: Nelore (NE), $1 / 2$ Aberdeen Angus + 1/2 Nelore (AN), 1/2 Canchim + 1/2 Nelore (CN) e $1 / 2$ Simental $+1 / 2$ Nelore (SN). 
Tabela 4 - Composição química do corte da 9â-10a-11aㅡ costela de quatro grupos genéticos em terminação

\begin{tabular}{|c|c|c|c|c|c|}
\hline \multirow[t]{2}{*}{ Variável } & \multicolumn{4}{|c|}{ Grupo genético ${ }^{1}$} & \multirow[t]{2}{*}{ Erro-padrão } \\
\hline & $\mathrm{AN}$ & $\mathrm{CN}$ & $\mathrm{NE}$ & SN & \\
\hline & \multicolumn{4}{|c|}{ Composição química do corte das costelas } & \\
\hline Água $(\%)$ & $47,93 \mathrm{~b}$ & $51,48 \mathrm{a}$ & $50,93 \mathrm{a}$ & $50,61 \mathrm{a}$ & 0,77 \\
\hline Proteína $(\%)$ & $16,08 \mathrm{a}$ & $16,87 \mathrm{a}$ & $16,85 \mathrm{a}$ & $16,82 \mathrm{a}$ & 0,41 \\
\hline Extrato etéreo (\%) & $28,73 \mathrm{a}$ & $24,51 \mathrm{~b}$ & $25,15 b$ & $25,04 \mathrm{~b}$ & 1,18 \\
\hline \multirow[t]{2}{*}{ Cinza $(\%)$} & $5,69 \mathrm{a}$ & $5,31 \mathrm{a}$ & $4,96 \mathrm{a}$ & $5,37 \mathrm{a}$ & 0,35 \\
\hline & \multicolumn{4}{|c|}{ Composição estimada do corpo vazio ao abate } & \\
\hline Água $(\%)$ & $56,78 b$ & $58,14 \mathrm{a}$ & $58,30 \mathrm{a}$ & $55,53 \mathrm{~b}$ & 0,46 \\
\hline Extrato etéreo $(\%)$ & $22,60 \mathrm{a}$ & $20,55 b$ & $20,40 b$ & $22,29 a$ & 0,54 \\
\hline Proteína bruta $(\%)$ & $16,55 \mathrm{c}$ & $17,10 \mathrm{~b}$ & $17,13 \mathrm{~b}$ & $17,80 \mathrm{a}$ & 0,07 \\
\hline Cinza $(\%)$ & $4,10 c$ & $4,20 \mathrm{~b}$ & $4,22 b$ & $4,38 \mathrm{a}$ & 0,01 \\
\hline Energia (Mcal/kg) & $3,06 \mathrm{a}$ & $2,90 \mathrm{~b}$ & $2,90 \mathrm{~b}$ & $3,10 \mathrm{a}$ & 0,04 \\
\hline
\end{tabular}

$1 \mathrm{NE}=$ Nelore $(n=8), A N=$ Aberdeen Angus $\times$ Nelore $(n=8), C N=$ Canchim $\times$ Nelore $(n=8), S N=$ Simental $\times$ Nelore $(n=7)$.

ab Letras distintas na mesma linha indicam diferença estatística pelo LSMeans a $5 \%$.

$\mathrm{AN}$ em relação aos bovinos do grupo $\mathrm{SN}$ ao mesmo peso (Tabela 2).

Maior porcentagem de ossos no corte foi encontrada nos animais $\mathrm{AN}, \mathrm{CN}$ e $\mathrm{SN}$ quando comparados àqueles da raça NE. Berndt et al. (2001), em avaliação de animais não castrados e dos mesmos grupos genéticos, encontraram resultados diferentes quanto à composição física do corte. Esses autores observaram maior percentual de gordura nos animais NE (32\%), valores intermediários nos CN (28\%) e AN (27\%) e menor valor no grupo SN (24,8\%). Entretanto, mesmo apresentando maior peso ao abate $(517,492,429$ e $537 \mathrm{~kg}$, dos animais AN, CN, NE e SN, respectivamente) os animais eram não-castrados e apresentaram menor percentual de gordura no corte (Berndt et al., 2001). Lanna et al. (1997) avaliaram a composição corporal de animais não castrados em ganho compensatório e não encontraram variação na composição física da carcaça entre os animais Nelore, Marchigiana $\times$ Nelore e mestiços de raça leiteira. A proporção de gordura separável (26,77; 23,51 e 25,06\%, nos animais Nelore, Marchigiana $\times$ Nelore e mestiços de raça leiteira, respectivamente) também foi inferior nos trabalhos de Lanna et al. (1997), provavelmente porque os animais eram não-castrados. O comportamento distinto dos animais castrados e não-castrados deve ser avaliado no futuro, mas talvez a nutrição inadequada (baixos níveis nutricionais no período de pastejo) tenha tido efeito significativo sobre a composição dos animais castrados deste estudo. Essa hipótese pode ser particularmente relevante para o grupo $\mathrm{SN}$, pois aparentemente estes animais tiveram seu crescimento permanentemente comprometido.

Quanto à composição química da 9âa-10a-11ạ costelas, animais AN apresentaram menor proporção de água e maior proporção de EE $(\mathrm{P}<0,05)$ em relação aos demais grupos estudados (Tabela 4). Entretanto, não houve diferença $(\mathrm{P}>0,05)$ entre os animais quanto ao percentual de proteína e de matéria mineral no corte das costelas. Lanna et al. (1997) encontraram maior proporção de água e menor proporção de EE nesse corte das costelas. Os resultados obtidos por esses autores estão relacionados ao fato de os animais serem machos não-castrados e estarem em crescimento compensatório, apesar da maior média de peso de carcaça $(283 \mathrm{~kg})$.

A composição do corpo vazio no momento do abate foi influenciada $(\mathrm{P}<0,05)$ pelo grupo genético. Animais $\mathrm{AN}$ e $\mathrm{SN}$ apresentaram maior proporção de EE e menor porcentagem de água em comparação aos outros grupos estudados (Tabela 4). O fato de os animais AN e SN terem ao abate a mesma composição corporal quanto à proporção de EE difere da literatura e sugere algumas questões. Uma hipótese é o comprometimento no crescimento do tecido ósseo de animais SN decorente de nutrição inadequada (baixo nível nutricional), resultando em deposição precoce de gordura. Essa afirmação está de acordo com os dados de Goulart et al. (2006), que avaliaram o comportamento do crescimento desses animais no período de cria e recria em sistema de pastagem e observaram ganhos de peso moderados e até mesmo negativos, o que levou à menor taxa de crescimento, principalmente dos mestiços de maior exigência (Simental $\times$ Nelore). A segunda hipótese é que também de ter havido superestimativa do teor de gordura pelas equações utilizadas para estimativa da composição corporal a partir do corte das costelas, uma vez que essas equações foram desenvolvidas com animais não-castrados.

Animais SN apresentaram o mesmo valor dos NE e dos CN de espessura de gordura subcutânea (Tabela 2). Espera-se que animais oriundos de cruzamentos com raças continen- 
tais, quando comparados a bovinos obtidos de cruzamentos com raças britânicas e zebuínas sejam maiores e mais pesados, tenham idade à maturidade mais tardia e carcaça mais magra à mesma idade (NRC, 1996). Entretanto, como mencionado anteriormente, o mesmo sistema de alimentação oferecido para os quatro grupos desde o nascimento pode ter levado à produção de carcaça com maior espessura de gordura subcutânea, peso bem mais leve que o esperado para os bovinos $\mathrm{SN}$.

Lanna (1988), em experimento com tourinhos da raça Nelore, avaliou o efeito do nível de ingestão de energia (ad libitume restrito) sobre as equações de estimativa da composição do corpo vazio baseadas na composição do corte da 9a-10 10 - 11 a costelas. Por meio do teste $\mathrm{t}$ foram testadas diferenças nos coeficientes lineares das equações para os dois níveis de ingestão. Não foram observadas diferenças estatísticas entre os coeficientes lineares das regressões de estimativa da composição corporal em porcentagem ou em quantidade dos componentes, entretanto houve tendência de diferença entre os valores dos coeficientes, cuja magnitude pode ter importância do ponto de vista biológico (Lanna, 1988). Nesse trabalho, o nível de ingestão de energia tendeu a alterar a equação de estimativa da porcentagem de água, o que sugere que tratamentos nutricionais podem modificar variáveis das equações de estimativa. Dessa forma, pelo fato de os animais utilizados por Berndt (dados não publicados) não terem passado por nenhum período de restrição alimentar em nenhuma fase de vida, é possível que essas equações não sejam as mais indicadas para os animais utilizados neste trabalho, que tiveram longos períodos de intensa restrição alimentar seguidos de período de crescimento compensatório em confinamento.

A porcentagem de minerais no corpo vazio foi semelhante à encontrada por Henrique et al. (2003), que obtiveram valor de 4,24\% em tourinhos da raça Santa Gertrudes. Esses autores encontraram, no corpo vazio, teores de proteína de $20,04 \%$ e de EE de $16,17 \%$, respectivamente. O maior teor de gordura dos animais deste trabalho é explicado, em parte, pelo maior peso (404 kg de peso vazio; Tabela 2), enquanto os animais avaliados por Henrique et al. (2003) foram abatidos com menor peso (321 kg de peso vazio).

Houve diferença entre os grupos genéticos quanto às taxas de deposição dos constituintes químicos corporais (Tabela 5). Animais AN apresentaram taxa de deposição de água de $530 \mathrm{~g} /$ dia, que não diferiu ( $\mathrm{P}>0,05$; Tabela 5) daquela dos NE (590 g/dia) e dos SN (510 g/dia). Entretanto, a deposição de gordura do grupo AN (530 g/dia) foi $23 \%$ maior $(\mathrm{P}<0,05)$ que a observada nos animais NE (430 g/dia) e CN (430 g/dia). Esse resultado sugere que o uso de animais de cruzamentos entre raças de origem britânica (Aberdeen Angus) e zebuína (Nelore) favorece a deposição de gordura em comparação ao uso de raças puras zebuínas ou de cruzados Canchim $\times$ Zebu. Bulle et al. (2002), em trabalho com tourinhos $1 / 4$ Bos indicus $+3 / 4$ Bos taurus de raça paterna britânica (Shorthorn) e continental (Guelbvieh), também encontraram maior deposição de gordura nos animais de raça paterna britânica, cuja deposição de gordura foi $8 \%$ maior que a dos animais oriundos de raça paterna continental. Esta maior deposição de gordura é consistente com a maior taxa de ganho e com a maior média de peso dos AN.

Bovinos AN diferiram $(\mathrm{P}<0,05)$ dos animais $\mathrm{CN}$ quanto à taxa de deposição de energia; esse resultado é reflexo do maior $(\mathrm{P}<0,05)$ ganho de peso do corpo vazio e do maior ganho de peso desses grupos (Tabela 5). Os animais SN e NE foram intermediários na sua taxa de deposição de energia. Berndt et al. (2003), em avaliação de tourinhos dos mesmos grupos genéticos, não encontraram diferença na taxa de deposição de energia (média de 5,17 Mcal/dia dos grupos AN, CN, NE e SN). Putrino et al. (2006) trabalharam com animais não-castrados com 28 meses de idade e relataram maior taxa de deposição de energia nos da raça Brangus (2,86 Mcal/dia) em comparação aos da raça Nelore (1,95 Mcal/dia). Putrino et al. (2006) encontraram valor de taxa de deposição de energia inferior ao deste trabalho, tanto para os animais da raça Brangus (2,86 Mcal/dia), quanto para os da raça Nelore (1,95 Mcal/dia). Esse comportamento apresentado por Putrino et al. (2006) pode ser explicado pelo fato de os animais serem não-castrados e apresentarem peso de abate inferior à média dos animais deste estudo. Ressalta-se que as diferenças genéticas neste trabalho envolvem apenas o efeito da raça paterna, visto que as mães eram do mesmo rebanho. Além disso, os touros Angus utilizados neste estudo eram de linhagens modernas, que apresentam elevado peso adulto e grau de estrutura corporal relativamente alto. Portanto, esperava-se que não apresentassem deposição de gordura excessivamente precoce. Mesmo não havendo diferença $(\mathrm{P}>0,05)$ quanto ao ganho de peso de corpo vazio entre os animais AN e SN, observou-se maior taxa de deposição de proteína nos animais oriundos da raça paterna continental (SN).

Em termos numéricos, animais AN apresentaram maior valor de EE $(41,50 \%)$ na composição do ganho de peso do corpo vazio em relação aos $\mathrm{NE}(\mathrm{P}<0,05)$, entretanto, não houve diferença $(\mathrm{P}>0,05)$ entre os bovinos da raça Nelore e dos grupos CN $(39,00 \%)$ e SN $(38,64 \%)$ (Tabela 5). Como mencionado, com peso final em jejum de $476 \mathrm{~kg}$, esperava-se menor valor de EE na composição do ganho de peso de 
Tabela 5 - Taxa de deposição dos componentes químicos corporais, composição do ganho de peso do corpo vazio e exigências líquidas para ganho de quatro grupos genéticos em terminação

\begin{tabular}{|c|c|c|c|c|c|}
\hline \multirow[t]{2}{*}{ Variável } & \multicolumn{4}{|c|}{ Grupo genético $^{1}$} & \multirow[t]{2}{*}{ Erro-padrão } \\
\hline & AN & $\mathrm{CN}$ & $\mathrm{NE}$ & SN & \\
\hline \multicolumn{6}{|l|}{ Taxa de deposição } \\
\hline Água (kg/dia) & $0,53 \mathrm{a}$ & $0,49 \mathrm{~b}$ & $0,59 \mathrm{a}$ & $0,51 \mathrm{ab}$ & 0,03 \\
\hline Extrato etéreo $(\mathrm{kg} / \mathrm{dia})$ & $0,53 \mathrm{a}$ & $0,43 b$ & $0,43 b$ & $0,49 \mathrm{ab}$ & 0,03 \\
\hline Proteína $(\mathrm{kg} / \mathrm{dia})$ & $0,18 b$ & $0,16 \mathrm{c}$ & $0,19 \mathrm{ab}$ & $0,20 \mathrm{a}$ & 0,01 \\
\hline Cinza (kg/dia) & $0,05 \mathrm{a}$ & $0,04 \mathrm{~b}$ & $0,05 \mathrm{a}$ & $0,05 \mathrm{a}$ & 0,002 \\
\hline Energia (Mcal/dia) & $6,06 \mathrm{a}$ & $5,00 \mathrm{~b}$ & $5,20 \mathrm{ab}$ & $5,80 \mathrm{ab}$ & 0,33 \\
\hline \multicolumn{6}{|c|}{ Composição do ganho de peso de corpo vazio (GPV) } \\
\hline Água $(\%)$ & $41,01 \mathrm{~b}$ & $43,36 a b$ & $46,63 \mathrm{a}$ & $41,00 \mathrm{~b}$ & 1,56 \\
\hline Extrato etéreo $(\%)$ & $41,50 \mathrm{a}$ & $39,00 \mathrm{ab}$ & $34,26 b$ & $38,64 \mathrm{ab}$ & 1,87 \\
\hline Proteína (\%) & $14,04 \mathrm{c}$ & $14,22 \mathrm{c}$ & $15,32 b$ & $16,33 \mathrm{a}$ & 0,24 \\
\hline Cinza $(\%)$ & $3,45 \mathrm{c}$ & $3,50 \mathrm{c}$ & $3,77 \mathrm{~b}$ & $4,03 \mathrm{a}$ & 0,06 \\
\hline \multicolumn{6}{|c|}{ Exigências líquidas para ganho } \\
\hline Energia (Mcal/kg GPVz) & $4,685 \mathrm{a}$ & $4,454 \mathrm{bc}$ & $4,081 \mathrm{c}$ & $4,482 b$ & 0,162 \\
\hline Proteína (kg/kg GPVz) & $0,140 \mathrm{c}$ & $0,142 \mathrm{c}$ & $0,153 b$ & $0,164 \mathrm{a}$ & 0,003 \\
\hline
\end{tabular}

$1 \mathrm{NE}=$ Nelore $(\mathrm{n}=8), \mathrm{AN}=$ Aberdeen Angus $\times$ Nelore $(\mathrm{n}=8), \mathrm{CN}=$ Canchim $\times$ Nelore $(n=8), \mathrm{SN}=\mathrm{Simental} \times \mathrm{Nelore}(\mathrm{n}=7)$.

ab Letras distintas na mesma linha indicam diferença estatística pelo LSMeans a $5 \%$.

corpo vazio dos animais SN. Contudo, estes animais apresentaram maior acabamento de carcaça, fato esse explicado pelo comprometimento do crescimento esquelético durante a fase de recria (Goulart et al., 2006).

Maior proporção de proteína (16,33\%) e de cinzas $(4,03)$ na composição do ganho de peso de corpo vazio $(\mathrm{P}<0,05)$ foi observada nos animais SN. Berndt et al. (2003) não encontraram diferença entre os grupos $\mathrm{AN}$ e $\mathrm{SN}$ quanto à proporção de proteína e de cinza na composição do corpo vazio. Entretanto, o grupo SN apresentou o maior teor de proteína no ganho. Putrino et al. (2006) observaram maior proporção de proteína e de cinzas na composição do ganho de peso do corpo vazio nos animais Nelore $(18,91 \%$ e $4,54 \%)$, quando comparados aos da raça Brangus (16,11 e $3,73 \%$, respectivamente).

As exigências de energia (Mcal/kg de ganho de peso vazio (GPVz) e de proteína ( $\mathrm{kg} / \mathrm{kg}$ de GPVz) foram diferentes entre os grupos genéticos avaliados (Tabela 5). Animais SN apresentaram a maior exigência de proteína $(0,164 \mathrm{~kg} / \mathrm{kg}$ de GPVz) e os grupos AN e CN, os menores valores (0,140 e $0,142 \mathrm{~kg} / \mathrm{kg}$ de GPVz, respectivamente) para essa variável. Os animais AN tiveram a maior exigência líquida de energia para ganho, tanto por unidade de ganho (4,70 Mcal/kg de GPVz) quanto por dia (6,06 Mcal/dia). Esta maior exigência do AN decorreu da maior taxa de ganho e da maior proporção de gordura no ganho, uma característica típica desta raça. Estas diferenças de exigências por quilograma de ganho de peso podem ser vistas como negativas, pois pioram a eficiência de conversão, mas também podem ser vistas como positivas, pois resultam em animais com melhor acabamento. Nesse contexto, o tipo de carne exigida por determinado mercado é fundamental para avaliar qual grupo genético é mais interessante.

Ferreira et al. (1998), avaliando as exigências líquidas para ganho de animais não-castrados Simental $\times$ Nelore com $500 \mathrm{~kg}$, observaram valores de proteína de $127 \mathrm{~g} / \mathrm{kg}$ de GPVz e de energia de 3,74 Mcal/kg de GPVz.

Fontes (1995) trabalhou com bovinos castrados da raça Nelore e cruzados Chianina $\times$ Nelore com média de $400 \mathrm{~kg}$ de peso de corpo vazio e 24 meses de idade, encontrou valores de exigência líquida de energia de 9,02 Mcal/kg de GPVz em animais da raça Nelore e de 5,27 Mca/kg de GPVz em mestiços das raças Chianina $\times$ Nelore. No entanto, esse autor encontrou valores de exigências de proteína para ganho de peso menores $(0,043 \mathrm{~kg} / \mathrm{kg}$ de GPVz e $0,120 \mathrm{~kg} / \mathrm{kg}$ de GPVz nos animais Nelore e nos Chianina $\times$ Nelore, respectivamente). Fontes (1995) justificou o menor valor de proteína para o Nelore pelo fato de os animais terem, ao entrar no confinamento, baixo potencial de crescimento muscular e, portanto, a maior parcela de energia foi utilizada para síntese de gordura. No entanto, os valores encontrados por Fontes (1995) quanto às exigências de proteína para ganho de peso $(0,043 \mathrm{~kg} / \mathrm{kg}$ de GPVz e $0,120 \mathrm{~kg} / \mathrm{kg}$ de GPVz nos animais Nelore e nos Chianina $\times$ Nelore, respectivamente), foram inferiores aos observados nos animais Nelore (0,153 kg/kg de GPVz) eSN $(0,164 \mathrm{~kg} / \mathrm{kg}$ de GPVz) deste trabalho. Lana et al. (1992), em estudo das exigências líquidas para ganho de animais castrados com $450 \mathrm{~kg}$ ao abate, observaram valores de proteína (44,80 g/kg de GPVz e 
$124,24 \mathrm{~g} / \mathrm{kg}$ de GPVz) inferiores aos deste trabalho e valores superiores de energia (8,40 Mcal/kg de GPVz e 5,21 Mcal/kg de GPVz) em animais da raça Nelore e cruzados Bos taurus $\times$ Nelore, respectivamente.

É interessante observar que as diferenças de composição corporal encontradas neste trabalho são pequenas e que diferenças no tempo de confinamento, e conseqüentemente no peso de abate, podem alterar significativamente esta composição corporal final. Os dados suportam a idéia de que animais cruzados Aberdeen Angus $\times$ Nelore são mais precoces e que animais cruzados com raças continentais apresentam menor taxa de deposição de gordura. A resposta diferente desses animais durante a recria, com o menor desempenho do Simental, sugere que estas raças têm aptidão para produzir carnes para mercados diversos (mais ou menos gordura) e que sua produtividade é função do manejo nutricional.

\section{Conclusões}

A composição corporal é influenciada pela raça ou pelo grupo genético do animal. Em mesma idade, bovinos resultantes do cruzamento das raças Aberdeen Angus e Nelore apresentam maiores pesos, maiores ganhos, maior acabamento e maior exigência de energia em comparação aos da raça Nelore e dos mestiços Canchim $\times$ Nelore e Simental $\times$ Nelore. Animais de grupos genéticos diferentes apresentaram taxas de deposição dos constituintes químicos corporais e exigências líquidas para ganho diferentes quando avaliados em mesma idade e mesmo manejo e sistema alimentar.

\section{Literatura Citada}

ALLEONI, G.F.; LEME, P.R.; BOIN, C. Avaliação da composição química e física dos cortes da costela para estimar a composição química corporal de novilhos nelore. Revista Brasileira de Zootecnia, v.26, n.2, p.382-390, 1997.

ALHASSAN, W.S.; BUCHANAN-SMITH, J.G.; USBORNE, W.R. et al. Predicting empty body composition of cattle from carcass weight and rib cut composition. Canadian Journal Animal Science, v.55, p.369-376, 1975.

ASSOCIATION OF OFFICIAL AGRICULTURAL CHEMISTS AOAC. Official methods of analysis of AOAC International. 16.ed. Arlington, 1995. v.2, p.10-11.

BERNDT, A.; CRUZ, G.M.; ALLEONI, G.F. et al. Tissue deposition rates and empty body composition of purebred and crossbred Nelore bulls. Journal of Animal Science, v.81, (suppl.1), p.306, 2003.

BERNDT, A.; CRUZ, G.M.; LANNA, D.P.D. et al. Composição física da $9-11^{\text {a }}$ costelas de tourinhos de diferentes grupos genéticos em confinamento em relação ao status nutricional na fase de pastejo. In: REUNIÃO DA SOCIEDADE BRASILEIRA DE ZOOTECNIA, 38., 2001, Piracicaba. Anais... Piracicaba: Sociedade Brasileira de Zootecnia, 2001. p.1302-1303.
BULLE, M.L.M.; RIBEIRO, F.G.; LEME, P.R. Exigência líquidas de energia e proteína de tourinhos de dois grupos genéticos alimentados com dietas de alto teor de concentrado. Revista Brasileira de Zootecnia, v.31, n.1, (supl 2), p.436-443, 2002.

FERREIRA, M.A.; VALADARES FILHO, S.C.; SILVA, J.F.C. Composição corporal e exigências líquidas de proteína e energia para ganho de peso de bovinos $\mathrm{F}_{1}$ Simental x Nelore. Revista Brasileira de Zootecnia, v.28, n.2, p.352-360, 1998.

FERRELL, C.L.; JENKINS, T.G. Relationships among various body components of mature cows. Journal of Animal Science, v.58, n.1, p.222-233, 1984.

FONTES, C.A.A. Composição corporal, exigências líquidas de nutrientes para ganho de peso e desempenho produtivo de animais zebuínos e mestiços europeu-zebu. Resultados experimentais. In: SIMPÓSIO INTERNACIONAL SOBRE EXIGÊNCIAS NUTRICIONAIS DE RUMINANTES, 1995, Viçosa, MG. Anais... Viçosa, mG: Universidade Federal de Viçosa, 1995. p.419-455.

FOX. D.G.; BLACK, J.R. A system for predicting body composition and performance of growing cattle. Journal of Animal Science, v.58, n.3, p.725-739, 1984.

FORTIN, A.; SIMPFENDORFER, S.; REID, J.T. et al. Effect of level of energy intake and influence of breed and sex on the chemical composition of cattle. Journal of Animal Science, v.51, n.3, p.604-614, 1980.

GARRETT, W.N.; MEYER, J.H.; LOFGREEN, G.P. The comparative energy requirements of sheep and cattle for maintenance and gain. Journal of Animal Science, v.18, p.528-547, 1959.

GOULART, R.S.; ALMEIDA, R.; POTT, E.B. et al. Desempenho de bovinos Nelore e cruzados "Bos taurus" x Nelore recriados em pastagem e terminados em confinamento. In: REUNIÃO ANUAL DA SOCIEDADE BRASILEIRA DE ZOOTECNIA, 43., 2006, João Pessoa. Anais... João Pessoa: Sociedade Brasileira de Zootecnia, 2006. (CD-ROM).

HAECKER, T.L. Investigations in beef production. Minnesota studies in plant science. Minneapolis: 1920. v.1, p.193.

HANKINS, O.G.; HOWE, P.E. Estimation of the composition of beef carcass cuts. Washington: United States Department of Agriculture, 1946. p.1-19 (Technical Bulletin - USDA, 926.)

HENRIQUE, W.; SAMPAIO, A.A.M.; LEME, P.R. et al. Estimativa da composição química corporal de tourinhos Santa Gertrudes a partir da composição química e física das 9-10-1 1 costelas. Revista Brasileira de Zootecnia, v.32, n.3, p.709-718, 2003.

LANA, R.P.; FONTES, C.A.A.; PERON, A.J. Composição corporal e do ganho de peso e exigências de energia, proteína e macroelementos minerais ( $\mathrm{Ca}, \mathrm{P}, \mathrm{Mg}, \mathrm{Na}$ e $\mathrm{K}$ ), de novilhos de cinco grupos raciais. 2. Exigências de energia e proteína. Revista da Sociedade Brasileira de Zootecnia, v.21, n.3, p.528537, 1992.

LANNA, D.P.D. Estimativa da composição química do corpo vazio de tourinhos Nelore através da gravidade específica da carcaça e da composição de cortes das costelas. Piracicaba: Escola Superior de Agricultura "Luiz de Queiroz", 1988. 131p. Dissertação (Mestrado em Ciência Animal e Pastagem) - Escola Superior de Agricultura "Luiz de Queiroz", 1988.

LANNA, D.P.D. Estimation of carcass and empty body composition of zebu bulls using the composition of rib cuts. Scientia Agricola, v.52, n.1, p.189-197, 1995.

LANNA, D.P.D.; BARIONI, L.G.; BOIN, C. et al. RLM 2.0: Ração de lucro máximo; versão 2.0, manual do usuário. Piracicaba: ESALQ, Departamento de Zootecnia, 1999. 26p.

LANNA, D.P.D.; LEME, P.R.; BOIN, C. et al. Ganho compensatório de bovinos de diferentes grupos genéticos: composição química e física corporal. In: REUNIÃO ANUAL DA SOCIEDADE BRASILEIRA DE ZOOTECNIA, 34., 1997, Juiz de Fora. Anais... Juiz de Fora: Sociedade Brasileira de Zootecnia, 1997. p.352-354.

LAWES, J.B.; GILBERT, J.H. Experimental inquiry into the composition of some of the animals fed and slaughtered as 
human food. Philosophical Transactions of the Royal Society of London.v.2, p.494, 1859 (Serie B).

LOFGREEN, G.P.; HULL, J.L.; OTAGAKI, K.K. Estimation of empty body weight of beef cattle. Journal of Animal Science, v.21, n.1, p.20-24, 1962.

NATIONAL RESEARCH COUNCIL - NRC. Nutrient requirements of beef cattle. 7.ed. Washington, D.C.: National Academy Press, 1996. 242p.

NATIONAL RESEARCH COUNCIL - NRC. Nutrient requirements of dairy cattle. 7.ed. Washington, D.C.: National Academy Science, 2001. 381p.

NOUR, A.Y.M.; THONNEY, M.L. Technical note: chemical composition of Angus and Holstein carcasses predicted from rib section composition. Journal of Animal Science, v.72, p.1239-1241, 1994.

PUTRINO, S.M.; LEME, P.R.; SILVA, S.L. Exigências líquidas de proteína e energia para ganho de peso de tourinhos Brangus e Nelore alimentados com dietas contendo diferentes proporções de concentrado. Revista Brasileira de Zootecnia, v.35, n.1, p.292-300, 2006.

REID, J.T. Body composition in animals: interspecific, sex, and age peculiarities, and the influence of nutrition. In: BREIREM, K.; MARICUDALS, B.A. (Eds.) Festkrift til. Gjovik: 1972.p.217-237.
REID, J.T.; WELLINGTON, G.H.; DUNN, H.O. Some relationships among the major chemical components of the bovine body and their application to nutritional investigations. Journal of Dairy Science, v.38, n.12, p.1344-1359, 1955.

REID, J.T.; BENSADOUN, A.; BULL, L.S. et al. Some peculiarities in the body composition of animals. In: NATIONAL RESEARCH COUNCIL. Body composition in animals and man. Washington: National Academy Press, 1968. p. 19-44.

REID, J.T.; WHITE, D.O.; ANDRIQUE, R.; FORTIN, A. Nutritional energetics of livestock: some present boundaries of knowledge and future research needs. Journal of Animal Science v. 51, p.1393, 1980 (suppl. 6).

SATISTICALANALYSIS SYSTEM - SAS. SAS/STAT user's guide. Version 8.2. 5.ed. Cary: 2001. 846p.

SIMPFENDORFER, S. Relationship of body type, size, sex, and energy intake to the body composition of cattle. Ithaca: Cornell University, 1974. 193p. Thesis (Ph.D.) - Cornell University, 1974.

WEISS, W.P.; CONRAD, H.R.; PIERRE, R.R.S. A theoretically based model for predicting total digestible nutrient values of forages and concentrates. Animal Feed Science Technology, v.39, p.95-110, 1992. 